\title{
A new prognostic histopathologic classification of nasopharyngeal carcinoma
}

\author{
Hai-Yun Wang ${ }^{1,2 \dagger}$, Yih-Leong Chang ${ }^{3 \dagger}$, Ka-Fai To ${ }^{4 \dagger}$, Jacqueline S. G. Hwang ${ }^{5 \dagger}$, Hai-Qiang Mai ${ }^{1,6 \dagger}$, \\ Yan-Fen Feng ${ }^{1,7}$, Ellen T. Chang ${ }^{8,9}$, Chen-Ping Wang ${ }^{10}$, Michael Koon Ming Kam ${ }^{11}$, Shie-Lee Cheah ${ }^{12}$, \\ Ming Lee ${ }^{5}$, Li Gao ${ }^{13}$, Hui-Zhong Zhang ${ }^{1,7}$, Jie-Hua He ${ }^{1,7}$, Hao Jiang ${ }^{14}$, Pei-Qing Ma ${ }^{15}$, Xiao-Dong Zhu ${ }^{16}$, \\ Liang Zeng ${ }^{17}$, Chun-Yan Chen ${ }^{1,18}$, Gang Chen ${ }^{19}$, Ma-Yan Huang ${ }^{1,7}$, Sha Fu ${ }^{1,2}$, Qiong Shao ${ }^{1,2}$, An-Jia Han ${ }^{20}$, \\ Hai-Gang Li ${ }^{21}$, Chun-Kui Shao ${ }^{22}$, Pei-Yu Huang ${ }^{1,6}$, Chao-Nan Qian ${ }^{1,6}$, Tai-Xiang Lu' ${ }^{17}$, Jin-Tian Li, ${ }^{1,23}$, \\ Weimin $\mathrm{Ye}^{24}$, Ingemar Ernberg ${ }^{25}$, Ho Keung Ng ${ }^{4}$, Joseph T. S. Wee ${ }^{11}$, Yi-Xin Zeng ${ }^{1,23}$, Hans-Olov Adami ${ }^{24,26}$, \\ Anthony T. C. Chan ${ }^{11^{*}}$ and Jian-Yong Shao ${ }^{1,2^{*}}$
}

\begin{abstract}
Background: The current World Health Organization (WHO) classification of nasopharyngeal carcinoma (NPC) conveys little prognostic information. This study aimed to propose an NPC histopathologic classification that can potentially be used to predict prognosis and treatment response.

Methods: We initially developed a histopathologic classification based on the morphologic traits and cell differentiation of tumors of 2716 NPC patients who were identified at Sun Yat-sen University Cancer Center (SYSUCC) (training cohort). Then, the proposed classification was applied to 1702 patients (retrospective validation cohort) from hospitals outside SYSUCC and 1613 patients (prospective validation cohort) from SYSUCC. The efficacy of radiochemotherapy and radiotherapy modalities was compared between the proposed subtypes. We used Cox proportional hazards models to estimate hazard ratios (HRs) with 95\% confidence intervals (Cl) for overall survival (OS).

Results: The 5-year OS rates for all NPC patients who were diagnosed with epithelial carcinoma (EC; 3708 patients), mixed sarcomatoid-epithelial carcinoma (MSEC; 1247 patients), sarcomatoid carcinoma (SC; 823 patients), and squamous cell carcinoma (SCC; 253 patients) were $79.4 \%, 70.5 \%, 59.6 \%$, and $42.6 \%$, respectively $(P<0.001)$. In multivariate models, patients with MSEC had a shorter OS than patients with $\mathrm{EC}(\mathrm{HR}=1.44,95 \% \mathrm{Cl}=1.27-1.62)$, SC $(\mathrm{HR}=2.00,95 \% \mathrm{Cl}=1.76-2.28)$, or SCC $(\mathrm{HR}=4.23,95 \% \mathrm{Cl}=3.34-5.38)$. Radiochemotherapy significantly improved survival compared with radiotherapy alone for patients with $\mathrm{EC}(\mathrm{HR}=0.67,95 \% \mathrm{Cl}=0.56-0.80)$, MSEC ( $\mathrm{HR}=0.58$, $95 \% \mathrm{Cl}=0.49-0.75)$, and possibly for those with SCC ( $\mathrm{HR}=0.63 ; 95 \% \mathrm{Cl}=0.40-0.98)$, but not for patients with SC $(\mathrm{HR}=0.97,95 \% \mathrm{Cl}=0.74-1.28)$.
\end{abstract}

Conclusions: The proposed classification offers more information for the prediction of NPC prognosis compared with the WHO classification and might be a valuable tool to guide treatment decisions for subtypes that are associated with a poor prognosis.

Keywords: Nasopharyngeal carcinoma, Pathologic classification, Prognosis

\footnotetext{
*Correspondence: shaojy@sysucc.org.cn; anthorny@cuhk.edu.hk

${ }^{\dagger}$ Hai-Yun Wang, Yih-Leong Chang, Ka-Fai To, Jacqueline S. G. Hwang and Hai-Qiang Mai contributed equally to this work

${ }^{1}$ State Key Laboratory of Oncology in South China; Collaborative

Innovation Center for Cancer Medicine, Sun Yat-sen University Cancer

Center, \#651 Dongfeng Road East, Guangzhou 510060, Guangdong, P. R.

China

Full list of author information is available at the end of the article
} provided you give appropriate credit to the original author(s) and the source, provide a link to the Creative Commons license, and indicate if changes were made. The Creative Commons Public Domain Dedication waiver (http://creativecommons.org/ publicdomain/zero/1.0/) applies to the data made available in this article, unless otherwise stated. 


\section{Background}

Nasopharyngeal carcinoma (NPC) is endemic in North Africa and Southeast Asia and most notably in South China, where the incidence can be as high as $20-40$ per 100,000 persons [1-3]. NPC differs from other head and neck cancers with regard to epidemiologic features, histopathologic features, treatment strategies, and response to therapy $[4,5]$. Based on the current World Health Organization (WHO) pathologic classification, NPCs are grouped into keratinizing squamous cell carcinoma (KSCC) and non-keratinizing carcinoma. The latter group is further subdivided into non-keratinizing differentiated carcinoma (NKDC) and non-keratinizing undifferentiated carcinoma (NKUC). However, this system is insufficiently informative, as clinical outcomes vary substantially among patients with the same clinical stage and histopathologic subtype [6-8]. Prognosis does not differ significantly between the NKUC and NKDC subtypes [8-10]. Pathologists have observed that NPC tumor cells have obvious morphologic variations, with cells that are small and round, large and round, spindleshaped, with or without vesicular nuclei, or mixed round and spindle-shaped. Despite this morphologic heterogeneity, proposed NPC histopathologic classifications to date have not demonstrated clinically relevant improvement in prognostic prediction beyond the WHO classification [11]. Therefore, clinicians have continued to appeal to pathologists to propose an NPC histopathologic classification system that better predicts prognosis and that enables personalized treatment of NPC patients.

In advanced NPC, radiochemotherapy (RCT) has been extensively investigated and demonstrated to improve tumor control and patient survival [12-17]. Two recent trials reported no survival benefit of concurrent RCT plus adjuvant chemotherapy versus concurrent RCT for advanced NPC; in addition, no survival benefit was reported with induction chemotherapy plus concurrent RCT versus induction chemotherapy plus radiotherapy (RT) alone for advanced NPC [16, 18]. Therefore, more accurate prognostication is needed to avoid over-treatment and to tailor treatment strategies that are compatible with individual risk patterns in a manner that improves patients' survival outcomes.

The primary objective of this large, multi-center study was to propose a histopathologic classification system for NPC that offers more information on prognosis than the WHO classification. A secondary, more exploratory objective was to determine whether patients with each histopathologic subtype benefit equally in terms of overall survival (OS) after RCT versus RT alone.

\section{Methods}

\section{Study design}

Figure 1 describes the criteria of patient selection and exclusion. In detail, the inclusion criteria were as follows: the availability of hematoxylin and eosin (H\&E) slides for review, the availability of follow-up data, no history of other treated cancer, and appropriate informed consent from patients. Patients with unknown treatment, unknown age or clinical stage, and those who received chemotherapy alone were excluded from this study. Patients who died from causes unrelated to NPC were also excluded. Two clinical staging systems were applied due to different geographic areas: patients from mainland China enrolled before 2006 were staged according to the 1992 China staging system [19], whereas patients from Hong Kong, Taiwan, Singapore, and Sun Yat-sen University Cancer Center (SYSUCC) who were enrolled between 2007 and 2011 were staged according to the 1997 American Joint Committee on Cancer (AJCC) staging system [20]. The ethics committee or institutional review board at each participating center approved the study.

\section{Morphologic features of each subtype of the proposed classification of NPC}

Representative features of each subtype of the proposed classification are shown in Fig. 2. NPCs were histologically classified into the following four subtypes based on morphologic features: epithelial carcinoma (EC), sarcomatoid carcinoma (SC), mixed sarcomatoid-epithelial carcinoma (MSEC), and squamous cell carcinoma (SCC). Specifically, EC is characterized by small, round tumor cells (Fig. 2a, b), large, round cells (Fig. 2c), or a carcinoma phenotype with vesicular nuclei (Fig. 2d). More than $50 \%$ of the tumor cells in SC are spindle-shaped, fusiform, or are in interlacing bundles (fibrosarcomatous pattern) (Fig. 2e-h). Morphologically, MSEC shows nests or scattered infiltration of large, round cells in spindle cell carcinomatous tissues (Fig. 2i-l). SCC is distinguished by tumor cells with a well differentiated keratinizing phenotype (Fig. $2 \mathrm{~m}, \mathrm{n}$ ) or a poorly or moderately differentiated phenotype (Fig. 2o, p).

\section{Inter-observer reproducibility of slide review}

Two experienced pathologists without knowledge of the clinical data independently classified all enrolled cases from each participating institution according to the proposed classification, and simultaneously reclassified all cases according to the WHO classification criteria. A third pathologist from the institution was consulted when the classifications of the first two pathologists 


\section{Primary analysis}

7565 NPC patients were diagnosed at the involved hospitals between 1995 and 2011

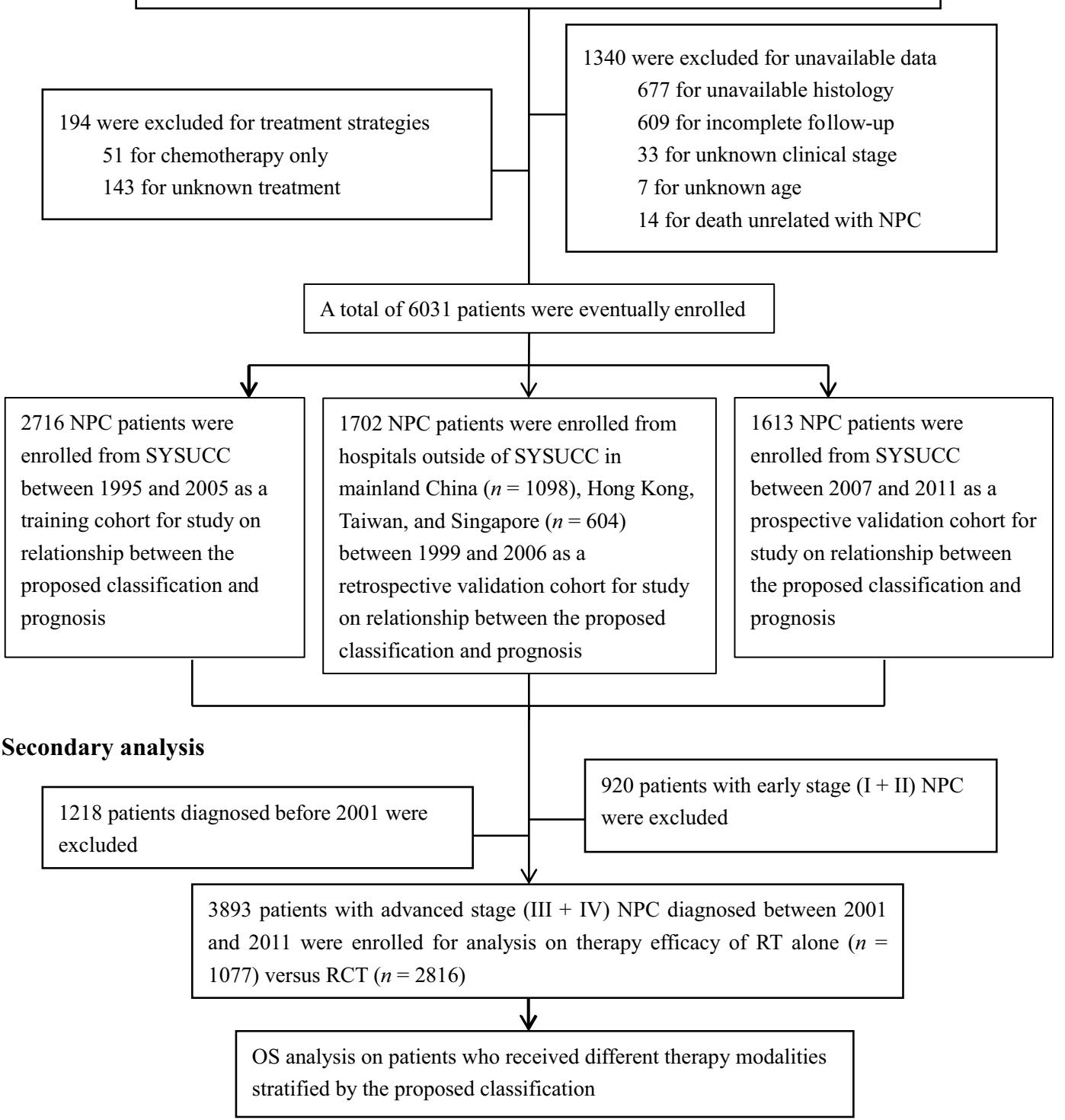

Fig. 1 Flowchart of the study design shows the inclusion and exclusions of nasopharyngeal carcinoma (NPC) patients with different therapeutic modalities stratified by the proposed classification. SYSUCC Sun Yat-sen University Cancer Center, OS overall survival, RT radiotherapy, RCT radiochemotherapy

conflicted. If the conclusion of the third pathologist was different, then the three worked collaboratively to reach an agreement. Inter-observer reproducibility of the results between the first two pathologists according to the new classification was $90.2 \%$ (Table 1 ).

\section{Efficacy of radiotherapy and radiochemotherapy}

The patients with advanced NPC who were diagnosed between 2001 and 2011 underwent further analysis of the therapeutic efficacy of RCT versus RT alone and were then stratified by the proposed classification; the 


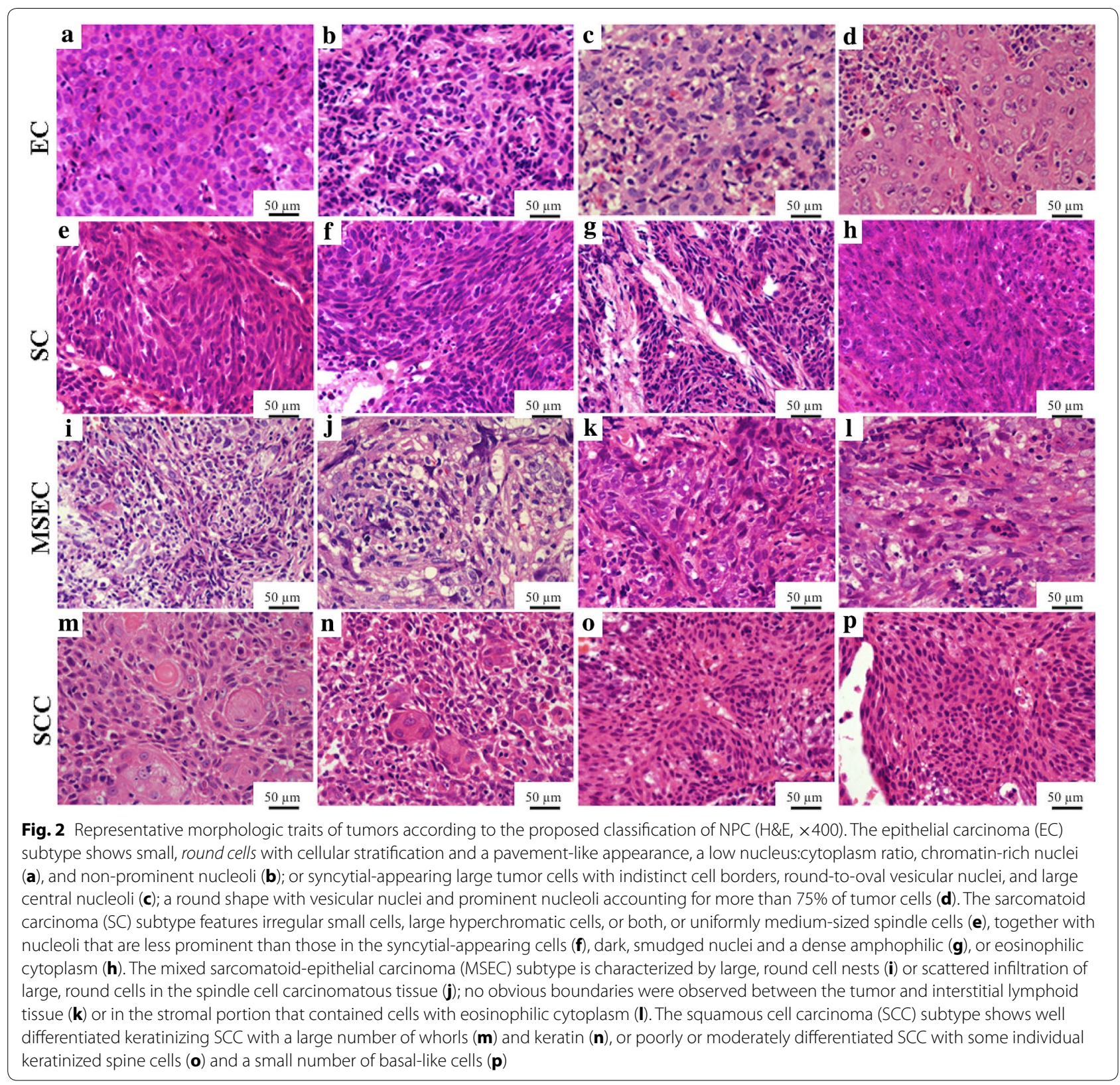

patients who were diagnosed before January 1, 2001, and those with early-stage disease were excluded to reduce variation in treatment protocols (Fig. 1). All patients with advanced NPC underwent standard curative RT, and some received additional chemotherapy. Patients in both groups received RT according to the policy at each center. The treatment protocol used at the largest contributing center was reported previously [21]. Generally, a regimen that consisted of 2 Gy per fraction, with 5 daily fractions per week, was used. A minimum dose of 60 Gy was given to gross tumor targets, while 50 Gy was given at sites of local infiltration and bilateral cervical lymphatic metastases. Patients who received RCT were administered neoadjuvant, concurrent, or adjuvant cisplatin (30$40 \mathrm{mg} / \mathrm{m}^{2}$ every week or $100 \mathrm{mg} / \mathrm{m}^{2}$ every 3 weeks) plus 5 -fluorouracil $\left(750 \mathrm{mg} / \mathrm{m}^{2}\right.$ per day, days $\left.1-5\right)$.

\section{Statistical analysis}

Probabilities of OS were estimated using the KaplanMeier method, and the log-rank test was used to detect differences among groups. We assessed the associations between clinical characteristics and subtypes of NPC classified according to the proposed classification using Student's $t$ test and the Chi square test. To test if 
Table 1 Inter-observer reproducibility between two pathologists based on the new nasopharyngeal carcinoma (NPC) histopathologic classification, stratified by area of case origin

\begin{tabular}{|c|c|c|c|}
\hline Case origin & $\begin{array}{l}\text { Consistent } \\
\text { (cases) }\end{array}$ & $\begin{array}{l}\text { Inconsistent } \\
\text { (cases) }\end{array}$ & $\begin{array}{l}\text { Reproducibility } \\
\text { (\%) }\end{array}$ \\
\hline $\begin{array}{l}\text { Sun Yat-sen University } \\
\text { Cancer Center } \\
\text { (SYSUCC) }\end{array}$ & 3067 & 325 & 90.3 \\
\hline $\begin{array}{l}\text { Other hospitals in } \\
\text { mainland China }\end{array}$ & 582 & 53 & 91.7 \\
\hline $\begin{array}{l}\text { Hong Kong, Taiwan, } \\
\text { Singapore }\end{array}$ & 535 & 77 & 87.4 \\
\hline Total & 4187 & 455 & 90.2 \\
\hline
\end{tabular}

In all, 4642 out of the 7565 patients in the initial database were assessed for the initial calculation of reproducibility

Table 2 Distribution of clinical centers where the 6031 enrolled nasopharyngeal carcinoma patients received a biopsy and therapy

\begin{tabular}{|c|c|c|}
\hline Center for biopsy & Center for therapy & $\begin{array}{l}\text { Number } \\
\text { of cases }\end{array}$ \\
\hline $\begin{array}{l}\text { Department of Pathology, Sun } \\
\text { Yat-sen University Cancer Center } \\
\text { (SYSUCC), Guangzhou, Guang- } \\
\text { dong, China }\end{array}$ & $\begin{array}{l}\text { Department of Radiation } \\
\text { Oncology, SYSUCC }\end{array}$ & 4329 \\
\hline $\begin{array}{l}\text { Department of Pathology, multi- } \\
\text { ple local centers in Guangdong, } \\
\text { China }\end{array}$ & $\begin{array}{l}\text { Department of Radiation } \\
\text { Oncology, SYSUCC }\end{array}$ & 504 \\
\hline $\begin{array}{l}\text { Department of Pathology, } \\
\text { Guangxi Medical University Can- } \\
\text { cer Center, Nanning, Guangxi, } \\
\text { China }\end{array}$ & $\begin{array}{l}\text { Department of Radiation } \\
\text { Oncology, Guangxi } \\
\text { Medical University } \\
\text { Cancer Center }\end{array}$ & 204 \\
\hline $\begin{array}{l}\text { Department of Pathology, Cancer } \\
\text { Institute and Hospital, Chinese } \\
\text { Academy of Medical Sciences } \\
\text { (CAMS), Beijing, China }\end{array}$ & $\begin{array}{l}\text { Department of Radiation } \\
\text { Oncology, Cancer } \\
\text { Hospital, CAMS }\end{array}$ & 100 \\
\hline $\begin{array}{l}\text { Department of Pathology, The } \\
\text { Affiliated Hospital of Bengbu } \\
\text { Medical College, Bengbu, Anhui, } \\
\text { China }\end{array}$ & $\begin{array}{l}\text { Department of Radiation } \\
\text { Oncology, The Affiliated } \\
\text { Hospital of Bengbu } \\
\text { Medical College }\end{array}$ & 113 \\
\hline $\begin{array}{l}\text { Department of Pathology, Hunan } \\
\text { Provincial Cancer Hospital, } \\
\text { Changsha, Hunan, China }\end{array}$ & $\begin{array}{l}\text { Department of Radiation } \\
\text { Oncology, Hunan Pro- } \\
\text { vincial Cancer Hospital }\end{array}$ & 130 \\
\hline $\begin{array}{l}\text { Department of Pathology, Fujian } \\
\text { Provincial Tumor Hospital, } \\
\text { Fuzhou, Fujian, China }\end{array}$ & $\begin{array}{l}\text { Department of Radiation } \\
\text { Oncology, Fujian Provin- } \\
\text { cial Tumor Hospital }\end{array}$ & 47 \\
\hline $\begin{array}{l}\text { Department of Anatomical and } \\
\text { Cellular Pathology, Faculty of } \\
\text { Medicine, the Chinese University } \\
\text { of Hong Kong (CUHK), Hong } \\
\text { Kong, China }\end{array}$ & $\begin{array}{l}\text { Department of Clinical } \\
\text { Oncology, CUHK }\end{array}$ & 207 \\
\hline $\begin{array}{l}\text { Department of Pathology, } \\
\text { National Taiwan University } \\
\text { Hospital, Taipei, Taiwan }\end{array}$ & $\begin{array}{l}\text { Department of Otolaryn- } \\
\text { gology, National Taiwan } \\
\text { University Hospital }\end{array}$ & 211 \\
\hline $\begin{array}{l}\text { Department of Pathology, } \\
\text { Singapore General Hospital, } \\
\text { Singapore, Singapore }\end{array}$ & $\begin{array}{l}\text { Department of Radiation } \\
\text { Oncology, National Can- } \\
\text { cer Center, Singapore }\end{array}$ & 186 \\
\hline
\end{tabular}

Table 3 Clinical characteristics of NPC patients in the training, retrospective validation, and prospective validation cohorts

\begin{tabular}{|c|c|c|c|}
\hline Characteristic & $\begin{array}{l}\text { Training } \\
\text { cohort }\end{array}$ & $\begin{array}{l}\text { Retrospective } \\
\text { validation } \\
\text { cohort }\end{array}$ & $\begin{array}{l}\text { Prospective } \\
\text { validation } \\
\text { cohort }\end{array}$ \\
\hline Total (cases) & 2716 & 1702 & 1613 \\
\hline \multicolumn{4}{|l|}{ Age (years) } \\
\hline Median (range) & $46(10-86)$ & $47(10-90)$ & $47(11-83)$ \\
\hline \multicolumn{4}{|c|}{ Follow-up time (months) } \\
\hline Median (range) & $68(1-120)$ & $68(1-120)$ & $41(1-91)$ \\
\hline \multicolumn{4}{|l|}{ Sex [cases (\%)] } \\
\hline Female & $658(24.2)$ & $501(29.4)$ & $404(25.1)$ \\
\hline Male & $2058(75.8)$ & $1201(70.6)$ & $1209(74.9)$ \\
\hline \multicolumn{4}{|c|}{ Clinical stage [cases (\%)] } \\
\hline । & $75(2.8)$ & $67(4.0)$ & $35(2.2)$ \\
\hline$\|$ & $549(20.2)$ & $388(22.8)$ & $104(6.5)$ \\
\hline III & $1272(46.8)$ & $695(40.8)$ & $458(28.4)$ \\
\hline IV & $820(30.2)$ & $552(32.4)$ & $1016(62.9)$ \\
\hline \multicolumn{4}{|c|}{ Therapeutic modality [cases (\%)] } \\
\hline $\begin{array}{l}\text { Radiotherapy } \\
\text { alone }\end{array}$ & $1592(58.6)$ & $928(54.5)$ & $220(13.6)$ \\
\hline $\begin{array}{l}\text { Radiochemo- } \\
\text { therapy }\end{array}$ & $1124(41.4)$ & $774(45.5)$ & $1393(86.4)$ \\
\hline \multicolumn{4}{|c|}{ Proposed classification [cases (\%)] } \\
\hline EC & $1520(55.9)$ & $987(58.0)$ & $1202(74.5)$ \\
\hline MSEC & $598(22.0)$ & $420(24.7)$ & $229(14.2)$ \\
\hline SC & $489(18.0)$ & $198(11.6)$ & $135(8.4)$ \\
\hline SCC & $109(4.1)$ & $97(5.7)$ & $47(2.9)$ \\
\hline \multicolumn{4}{|c|}{ WHO classification [case (\%)] } \\
\hline NKUC & $2261(83.2)$ & $1425(83.8)$ & $1185(73.5)$ \\
\hline NKDC & $409(15.1)$ & $227(13.3)$ & $414(25.7)$ \\
\hline $\mathrm{KSCC}$ & $46(1.7)$ & $50(2.9)$ & $14(0.8)$ \\
\hline \multicolumn{4}{|l|}{ OS rate (\%) } \\
\hline 5-year $(95 \% \mathrm{Cl})$ & 68.7 (66.9-70.5) & $73.3(71.1-75.4)$ & $83.5(81.1-85.6)$ \\
\hline
\end{tabular}

NPC nasopharyngeal carcinoma, EC epithelial carcinoma, SC sarcomatoid carcinoma, MSEC mixed sarcomatoid-epithelial carcinoma, SCC squamous cell carcinoma, WHO World Health Organization, NKUC non-keratinizing undifferentiated carcinoma, NKDC non-keratinizing differentiated carcinoma, KSCC keratinizing squamous cell carcinoma, OS overall survival, $\mathrm{Cl}$ confidence interval

the proposed classification was an independent prognostic factor of OS, we adjusted for age, sex, clinical stage, therapeutic modality, and the WHO classification and used multivariate Cox proportional hazards regression models to estimate hazard ratios (HRs) with $95 \%$ confidence intervals (CI). The heterogeneity according to clinical stage in the association between histopathologic classification and OS was examined by the inclusion of an interaction term between stage and histology and by the stratification of models by stage at diagnosis. The patients were followed every 6 months, and a 5-year follow-up 


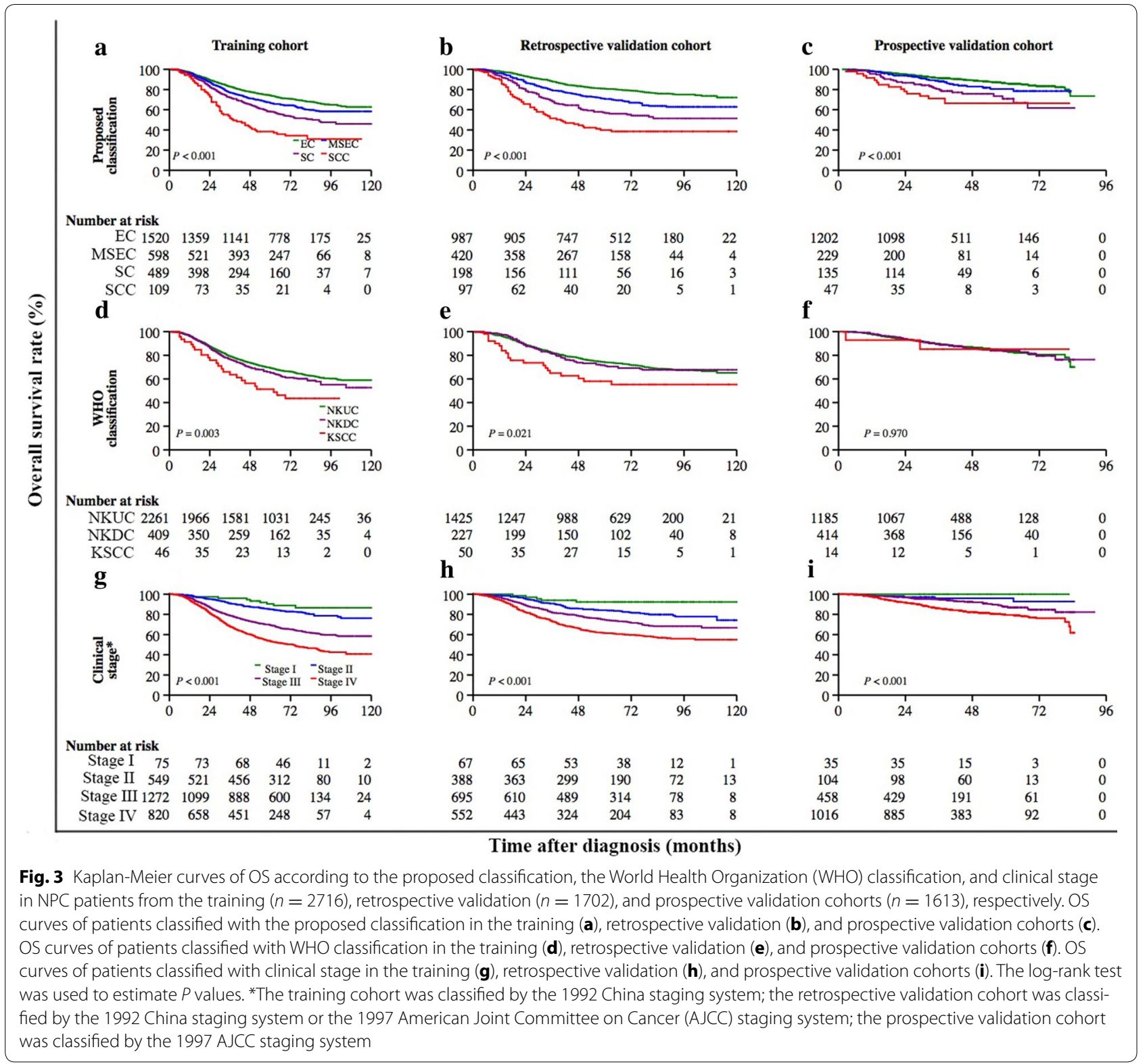

was achieved for $75.9 \%$ (4583/6031) of the NPC patients. However, enrollment in the prospective validation cohort continued until as recently as 2011, and follow-up data were recorded until April 2, 2015; therefore, the 5-year follow-up rate was $38.5 \%$ in this cohort. We calculated the OS from the date of diagnosis until the date of death of NPC or the last date of follow-up. All statistical tests were two-sided, and a $P$ value of less than 0.05 was considered statistically significant. All statistical analyses were performed with Stata software (version 13, the University of California, Los Angeles, CA, USA).

\section{Results}

\section{Patient characteristics}

This study enrolled 6031 patients with newly diagnosed, histologically confirmed, previously untreated NPC: 4329 were enrolled from SYSUCC in Guangzhou, China, 604 from Hong Kong, Taiwan, and Singapore, and 1098 from other institutions in mainland China (Table 2). Table 3 summarizes the demographic and clinical characteristics of NPC patients in the training, retrospective validation, and prospective validation cohorts, who were followed up for a median of 68,68 , and 41 months, respectively. NPC 
patients in the training cohort $(n=2716)$ from SYSUCC and the retrospective validation cohort from other hospitals in mainland China $(n=1098)$ were staged according to the 1992 China staging system. Patients from Hong Kong, Taiwan, and Singapore in the retrospective validation cohort $(n=604)$ as well as patients from SYSUCC in the prospective validation cohort $(n=1613)$ were staged according to the 1997 AJCC staging system (Fig. 1).

\section{The proposed classification of NPC and patient survival}

The 5-year OS rates in the training, retrospective validation, and prospective validation cohorts were $68.7 \%$, $73.3 \%$, and $83.5 \%$, respectively (Table 3 ). Figure 3 displays that the differences in OS curves were significant for patients classified with the proposed classification system $(P<0.001)$ as well as for patients classified with clinical stage $(P<0.001)$ in each cohort. However, no difference was observed between the NKUC and NKDC subtypes, although the difference in OS of patients stratified by WHO classification remained significant in the training cohort $(P=0.003)$ and retrospective validation cohort $(P=0.021)$.

Because the association between the proposed classification and the 5-year OS was similar across the three cohorts, we combined all 6031 NPC patients for subsequent analysis. In all NPC patients, the 5-year OS rates for the EC, MSEC, SC, and SCC subtypes were 79.4\%, $70.5 \%, 59.6 \%$, and $42.6 \%$, respectively (Table 4 ). The difference in the 5 -year OS rate was $8.9 \%$ between the most common subtypes (EC and MSEC), which together comprised $82.2 \%$ of all patients; the difference was $19.8 \%$ between the EC and SC subtypes, which together comprised $75.1 \%$ of all patients; the difference was $17.0 \%$ between the poor-prognosis subtypes SC and SCC, which together comprised $17.8 \%$ of all patients in the study. These significant differences indicate that the

Table 4 Cox proportional regression analysis of the associations between patient characteristics and OS in all 6031 NPC patients

\begin{tabular}{|c|c|c|c|c|c|c|c|c|c|}
\hline \multirow[t]{2}{*}{ Characteristic } & \multirow{2}{*}{$\begin{array}{l}\text { Patients } \\
\text { [cases (\%)] }\end{array}$} & \multicolumn{2}{|c|}{ OS rate (\%) } & \multirow{2}{*}{$\begin{array}{l}\text { Unadjusted } \\
\text { HR }\end{array}$} & \multirow[t]{2}{*}{$95 \% \mathrm{Cl}$} & \multirow[t]{2}{*}{$P$ value } & \multirow{2}{*}{$\begin{array}{l}\text { Adjusted } \\
\mathrm{HR}^{\mathrm{a}}\end{array}$} & \multirow[t]{2}{*}{$95 \% \mathrm{Cl}$} & \multirow[t]{2}{*}{$P$ value } \\
\hline & & 5-year & $95 \% \mathrm{Cl}$ & & & & & & \\
\hline \multicolumn{10}{|l|}{ Proposed classification } \\
\hline EC & $3708(61.5)$ & 79.4 & $78.1-80.8$ & 1.00 & Reference & & 1.00 & Reference & \\
\hline MSEC & $1247(20.7)$ & 70.5 & $67.7-73.0$ & 1.48 & $1.32-1.67$ & $<0.001$ & 1.44 & $1.27-1.62$ & $<0.001$ \\
\hline SC & $823(13.6)$ & 59.6 & $55.9-63.1$ & 2.16 & $1.90-2.44$ & $<0.001$ & 2.00 & $1.76-2.28$ & $<0.001$ \\
\hline SCC & $253(4.2)$ & 42.6 & $35.8-49.3$ & 3.56 & $2.96-4.28$ & $<0.001$ & 4.23 & $3.34-5.38$ & $<0.001$ \\
\hline \multicolumn{10}{|l|}{ Age } \\
\hline$\leq 47$ years & $3163(52.5)$ & 77.8 & $76.3-79.3$ & 1.00 & Reference & & 1.00 & Reference & \\
\hline$>47$ years & $2868(47.5)$ & 68.4 & $66.6-70.2$ & 1.54 & $1.40-1.70$ & $<0.001$ & 1.50 & $1.36-1.65$ & $<0.001$ \\
\hline \multicolumn{10}{|l|}{ Sex } \\
\hline Male & $4468(74.1)$ & 71.7 & $70.3-73.1$ & 1.00 & Reference & & 1.00 & Reference & \\
\hline Female & $1563(25.9)$ & 78.1 & $75.8-80.2$ & 0.73 & $0.65-0.81$ & $<0.001$ & 0.76 & $0.68-0.86$ & $<0.001$ \\
\hline \multicolumn{10}{|l|}{ Therapeutic modality } \\
\hline Radiotherapy alone & $2739(45.4)$ & 71.4 & $69.6-73.1$ & 1.00 & Reference & & 1.00 & Reference & \\
\hline Radiochemotherapy & $3292(54.6)$ & 75.2 & $73.4-76.8$ & 0.88 & $0.79-0.97$ & 0.009 & 0.65 & $0.59-0.72$ & $<0.001$ \\
\hline \multicolumn{10}{|l|}{ Clinical stage } \\
\hline I & $177(2.9)$ & 92.4 & $87.1-95.5$ & 1.00 & Reference & & 1.00 & Reference & \\
\hline$\|$ & $1041(17.3)$ & 85.6 & $83.2-87.6$ & 2.20 & $1.27-3.79$ & 0.004 & 2.25 & $1.3-3.89$ & 0.003 \\
\hline III & $2424(40.2)$ & 74.3 & $72.4-76.0$ & 4.17 & $2.46-7.08$ & $<0.001$ & 4.70 & $2.76-7.98$ & $<0.001$ \\
\hline IV & $2389(39.6)$ & 64.9 & $62.7-67.0$ & 5.77 & $3.40-9.78$ & $<0.001$ & 6.96 & $4.09-11.85$ & $<0.001$ \\
\hline \multicolumn{10}{|l|}{ WHO classification } \\
\hline NKUC & $4871(80.8)$ & 73.8 & $72.5-75.1$ & 1.00 & Reference & & 1.00 & Reference & \\
\hline NKDC & $1050(17.4)$ & 73.2 & $70.1-75.9$ & 1.02 & $0.90-1.16$ & 0.729 & 1.00 & $0.87-1.16$ & 0.980 \\
\hline $\mathrm{KSCC}$ & $110(1.8)$ & 57.5 & $47.0-66.6$ & 1.85 & $1.38-2.47$ & $<0.001$ & 0.51 & $0.35-0.74$ & $<0.001$ \\
\hline
\end{tabular}

OS overall survival, NPC nasopharyngeal carcinoma, HR hazard ratio, Cl confidence interval, EC epithelial carcinoma, MSEC mixed sarcomatoid-epithelial carcinoma, SC sarcomatoid carcinoma, SCC squamous cell carcinoma, WHO World Health Organization, NKUC non-keratinizing undifferentiated carcinoma, NKDC non-keratinizing differentiated carcinoma, KSCC keratinizing squamous cell carcinoma

a All models were adjusted for the proposed classification, age, sex, therapeutic modality, clinical stage, and WHO classification 


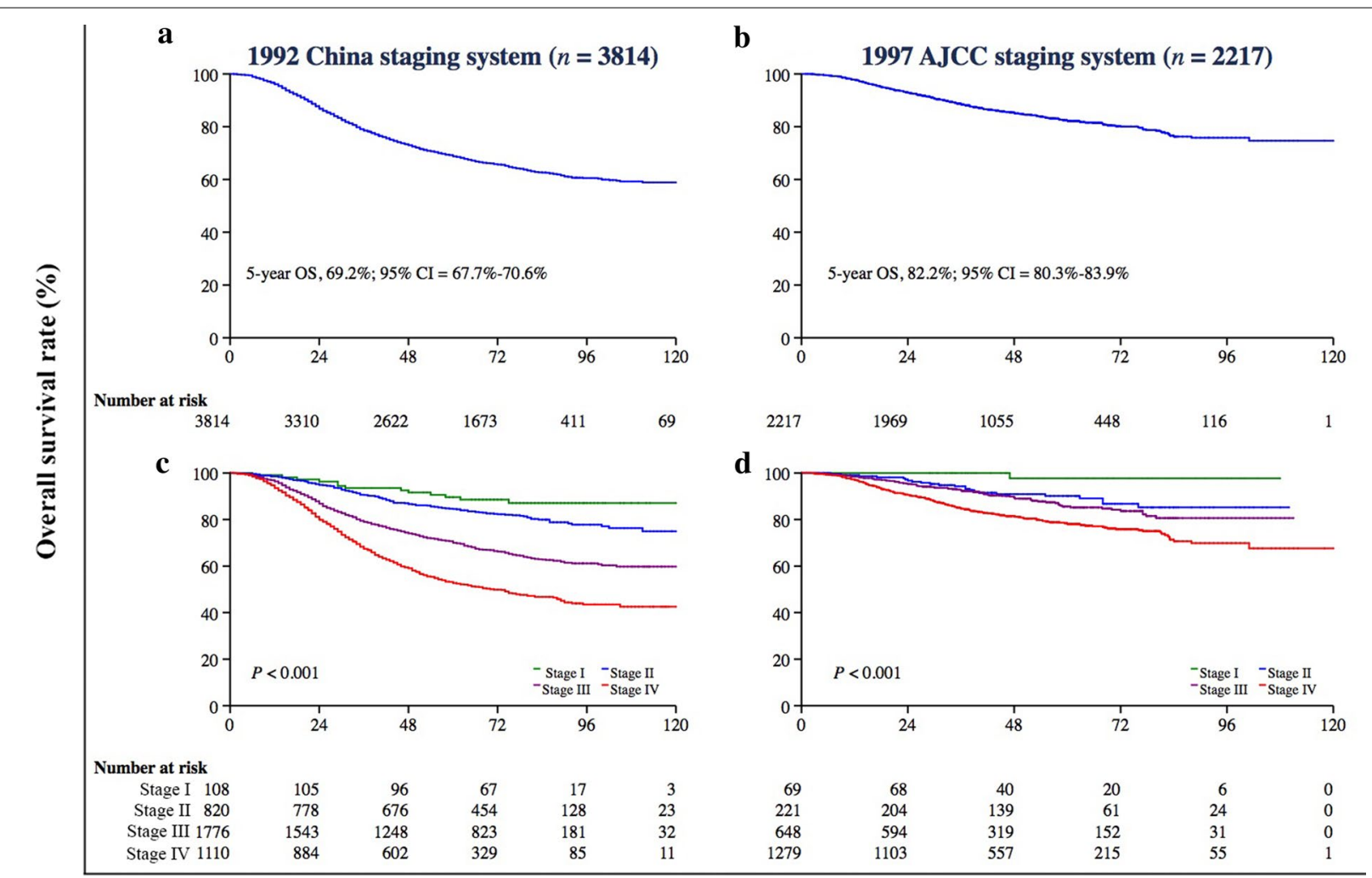

Time after diagnosis (months)

Fig. 4 Kaplan-Meier survival estimates for NPC patients according to two different staging systems. In all, 3814 (63.2\%) NPC patients from mainland China were diagnosed before 2006 and were staged according to the 1992 China staging system, whereas 2217 (36.8\%) from Hong Kong, Taiwan, Singapore, and SYSUCC (in mainland China) were diagnosed between 2007 and 2011 and were staged according to the 1997 AJCC staging system. The 5-year OS rate was $69.2 \%(95 \% \mathrm{Cl}=67.7 \%-70.6 \%)$ for patients classified by the 1992 China staging system $(\mathbf{a})$ and $82.2 \%(95 \% \mathrm{Cl}=80.3 \%-$ 83.9\%) for patients classified by the 1997 AJCC staging system (b). The OS differed significantly by clinical stage according to the 1992 China staging system $(P<0.001, \mathbf{c})$ and the 1997 AJCC staging system $(P<0.001$, d). The log-rank test was used to calculate $P$ values

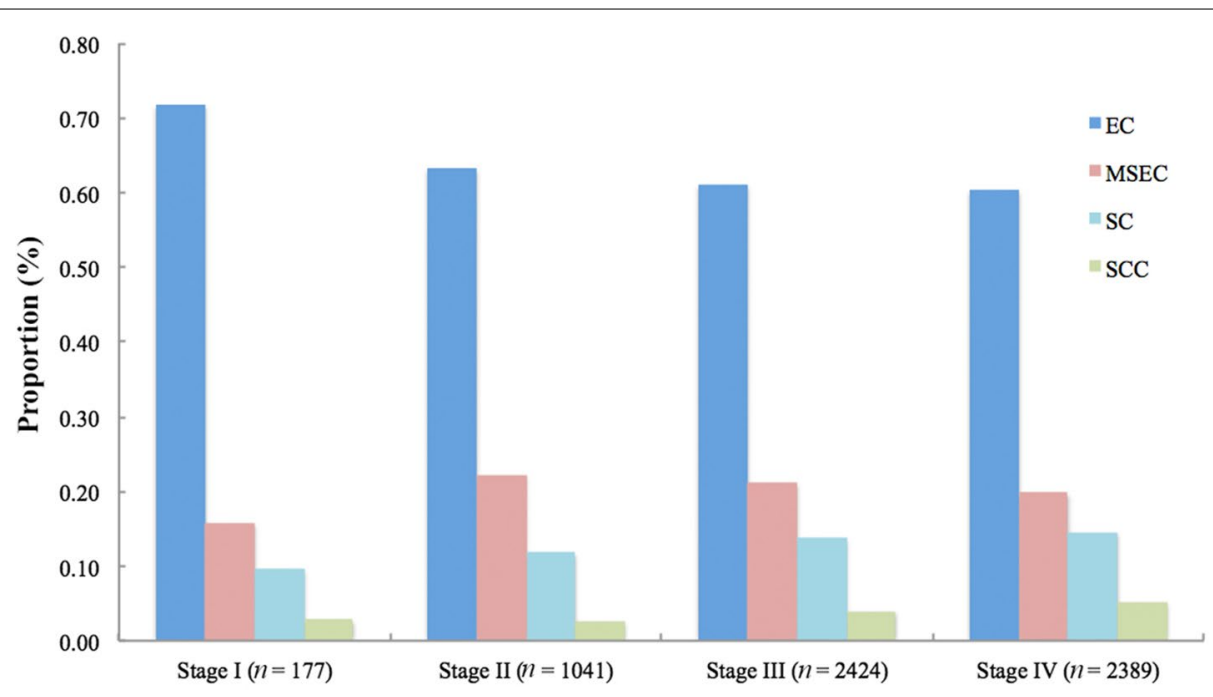

Fig. 5 Associations between clinical stage and the proposed histopathologic classification in all NPC patients. The proportions of EC cases are 71.8\%, 63.3\%, 61.1\%, and 60.4\% in patients with stages I, II, III, and IV NPC (the 1992 China and 1997 AJCC staging systems combined), respectively, whereas those of SC cases are 9.6\%, 11.8\%, 13.7\%, and 14.6\%, respectively. The proportion of SC increased with advanced stage, whereas the proportion of EC decreased with more advanced stage (Chi square test, $P=0.001$ ) 
proposed classification can distinguish the prognosis of NPC patients. By contrast, according to the WHO classification, a difference of only $0.6 \%$ was detected between the two most common subtypes (NKUC and NKDC), which together comprised $98.2 \%$ of all patients. NKUC cases were reclassified by the proposed classification primarily as EC (60.0\%) and as MSEC (24.2\%), whereas NKDC cases were reclassified primarily as EC (81.3\%) (Chi square test, $P<0.001$ ).

\section{The association between clinical stage and the proposed NPC classification}

Different clinical staging systems were adopted in this study. The 5-year OS rate was $69.2 \%$ (95\% CI $=67.7 \%$ $70.6 \%$ ) for patients who were classified according to the 1992 China staging system (Fig. 4a) and was $82.2 \%$ (95\% CI $=80.3 \%-83.9 \%)$ for patients who were classified according to the 1997 AJCC staging system (Fig. 4b). The association between the proposed classification and clinical stage was statistically significant when both staging systems were combined (Chi square test, $P<0.001$; Fig. 5). After stratification by the combination of both clinical staging systems, the proposed classification still remained a significant predictor of prognosis in all NPC patients (Fig. 6). In the three cohorts that were examined separately, the proposed classification retained significance in the prediction of prognosis, especially in NPC patients with stages III and IV cancers, who accounted for approximately $80 \%$ of the enrolled patients (Fig. 7). This remained true irrespective of whether the clinical stage was determined according to the 1992 China staging system or the 1997 AJCC staging system (Fig. 8).

\section{Multivariate analysis of OS according to the proposed classification}

The proportional hazards assumption for each covariate was tested by graphical methods, and no significant violations were found. In the univariate analyses of OS for all NPC patients, the subtypes of MSEC, SC, and

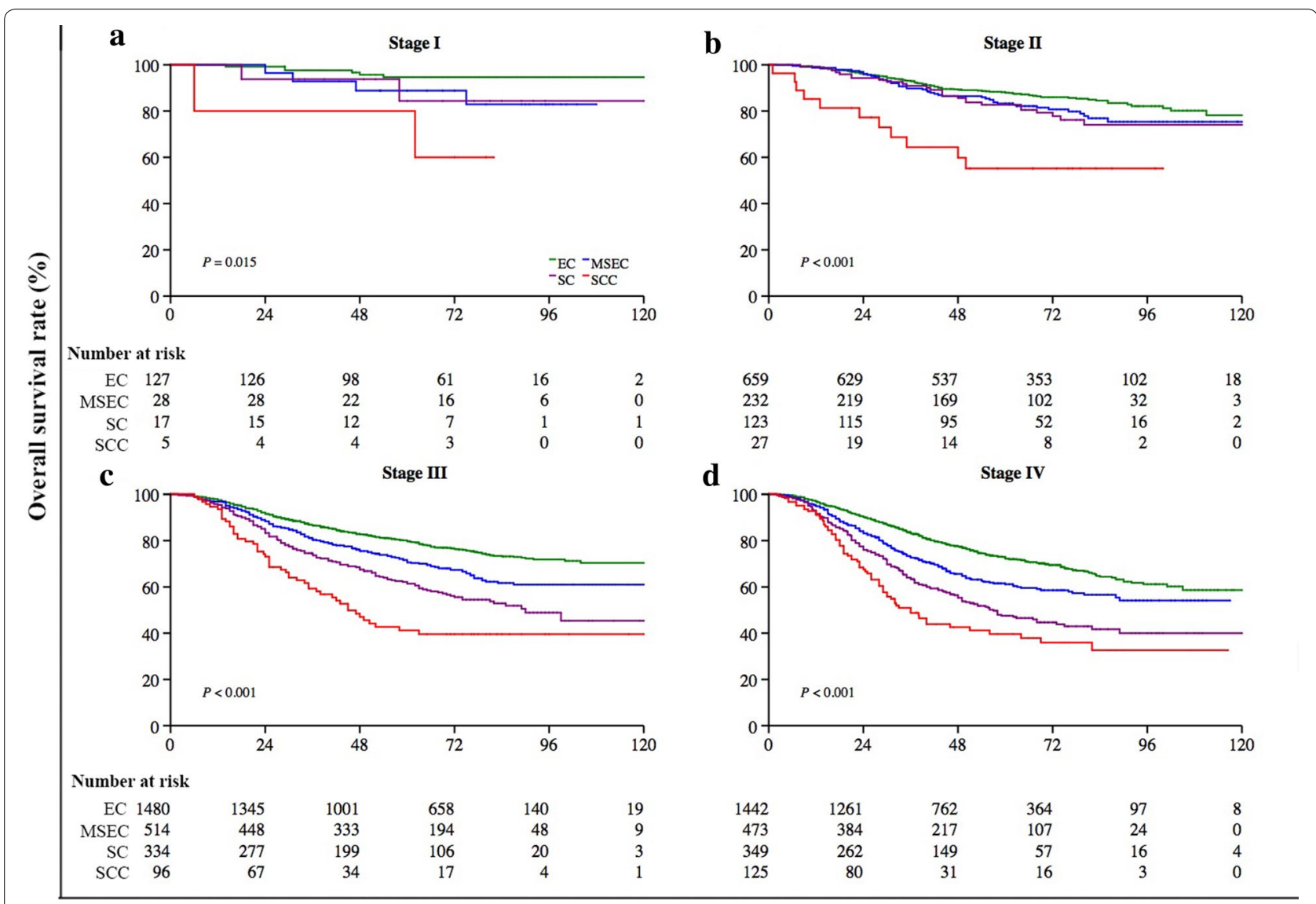

Time after diagnosis (months)

Fig. 6 Kaplan-Meier survival estimates for NPC patients at different clinical stages (the 1992 China and 1997 AJCC staging systems combined) stratified by subtypes according to the proposed histopathologic classification. The OS differed significantly by the proposed classification for patients with stage I $(P=0.015, \mathbf{a})$, II $(P<0.001, \mathbf{b})$, III $(P<0.001, \mathbf{c})$, or IV disease $(P<0.001$, d). The log-rank test was used to calculate $P$ values 


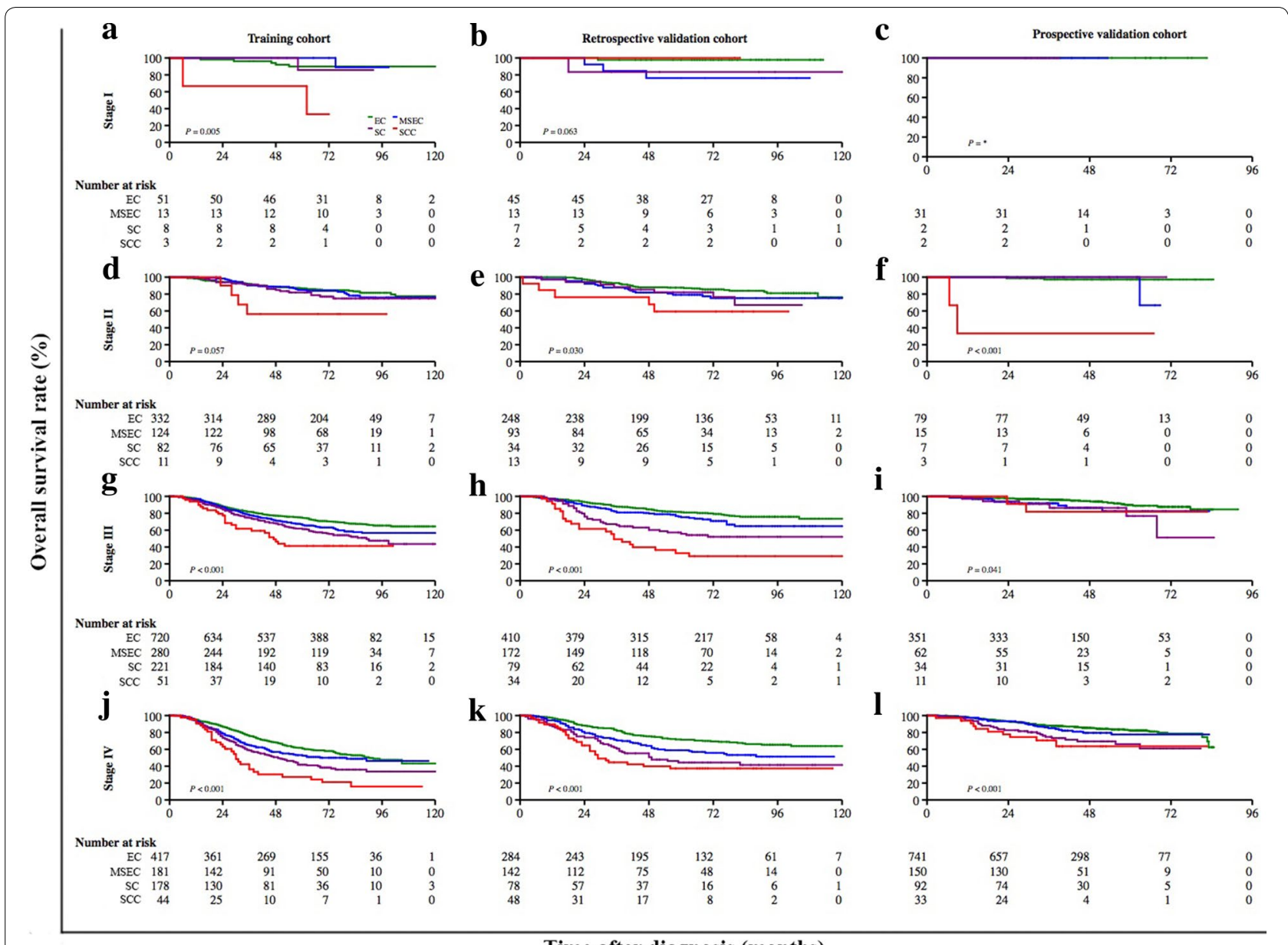

Time after diagnosis (months)

Fig. 7 Kaplan-Meier survival estimates for NPC patients at different clinical stages in three separate cohorts stratified by subtypes according to the proposed classification. OS curves of NPC patients stratified by subtypes according to the proposed classification with stage I $(P=0.005$, a; $(P=0.063, \mathbf{b} ; \mathbf{c}), \|(P=0.057, \mathbf{d} ; P=0.030, \mathbf{e} ;$ and $P<0.001, \mathbf{f}), \| I(P<0.001, \mathbf{g}$ and $\mathbf{h} ; P=0.041, \mathbf{i})$, and IV disease $(P<0.001, \mathbf{j}, \mathbf{k}$, and $\mathbf{l})$ in the training, retrospective validation, and prospective validation cohorts, respectively. The log-rank test was used to calculate $P$ values. ${ }^{*}$ No test possible because there were no failures

SCC, older age, male sex, RT alone, and advanced clinical stage were associated with significantly shorter OS (Table 4). In the multivariate analysis, the proposed classification independently predicted OS even after adjustments for age, sex, therapeutic modality, tumor stage, and WHO classification. Compared with EC, the HR was 1.44 (95\% CI $=1.27-162, P<0.001)$ for MSEC, 2.00 $(95 \% \mathrm{CI}=1.76-2.28, P<0.001)$ for $\mathrm{SC}$, and $4.23(95 \%$ CI $=3.34-5.38, P<0.001)$ for SCC (Table 4). After multivariate adjustment, the SC subtype predicted a higher risk of death compared with the MSEC subtype $(\mathrm{HR}=1.40,95 \% \mathrm{CI}=1.21-1.61, P<0.001)$; moreover, SCC was associated with a higher risk of death compared with SC $(\mathrm{HR}=2.11,95 \% \mathrm{CI}=1.63-2.75, P<0.001)$ (data not shown).

\section{Therapeutic efficacy of RCT versus $R T$ alone}

Overall, 3893 patients with advanced NPC who were diagnosed between 2001 and 2011 were stratified by the proposed classification and underwent further analysis to determine the therapeutic efficacy of RCT versus RT alone (Fig. 1). The baseline demographic and clinical characteristics of patients with advanced NPC who were treated with RCT $(n=2816)$ or RT alone $(n=1077)$ are shown in Table 5 . The 5 -year OS rates of patients with advanced NPC differed significantly between the RCT and RT alone groups $(75.6 \%$ vs. $64.8 \%, P<0.001)$. RCT prolonged OS as compared with RT alone for patients with the EC subtype $(\mathrm{HR}=0.67,95 \% \mathrm{CI}=0.56-0.80$, $P<0.001$; Fig. 9a) and the MSEC subtype $(\mathrm{HR}=0.58$, 95\% CI $=0.49-0.75, P<0.001$; Fig. 9b), but not for 

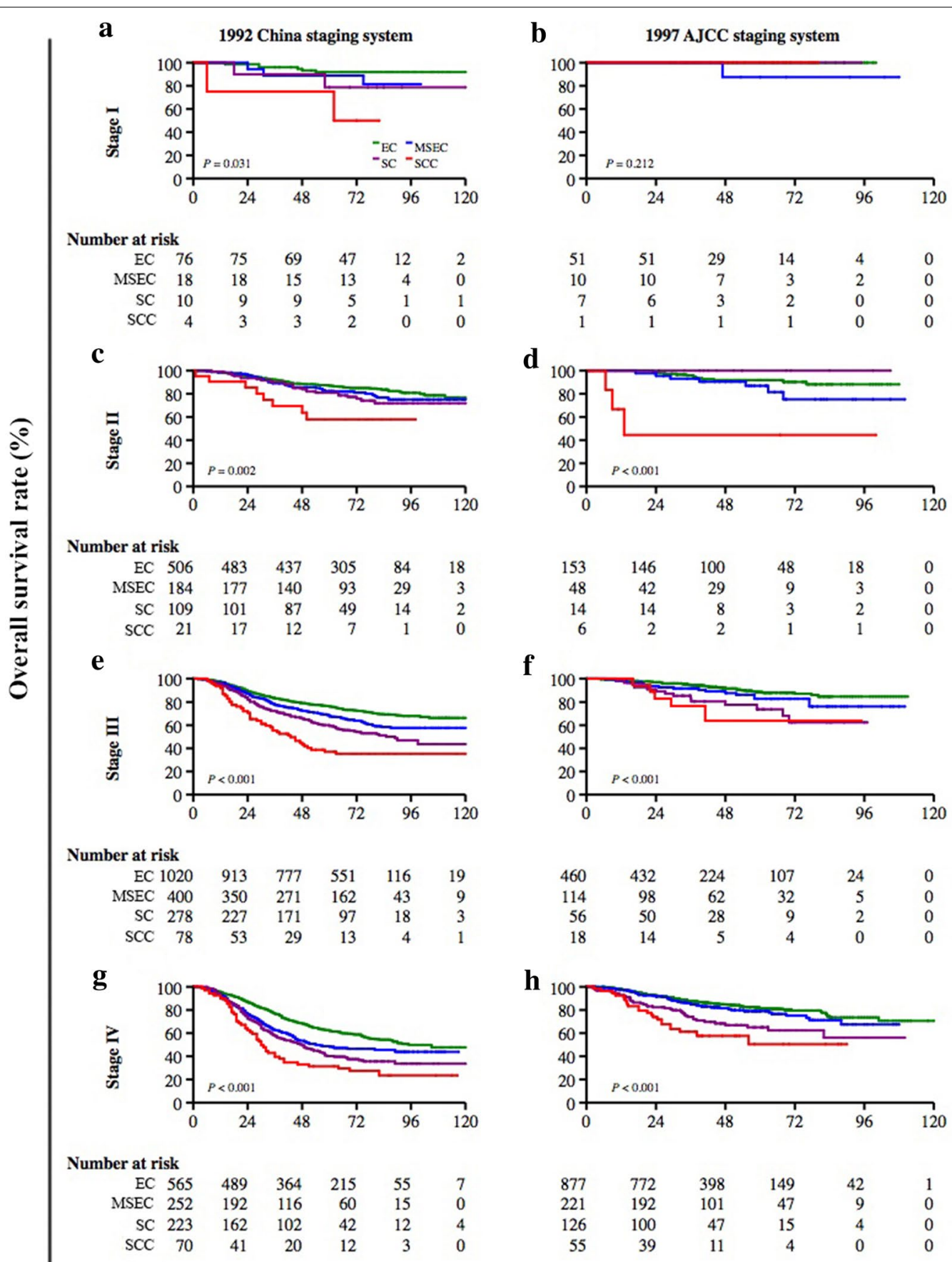

$\begin{array}{rrrrrr}51 & 51 & 29 & 14 & 4 & 0 \\ 10 & 10 & 7 & 3 & 2 & 0 \\ 7 & 6 & 3 & 2 & 0 & 0 \\ 1 & 1 & 1 & 1 & 0 & 0\end{array}$

d
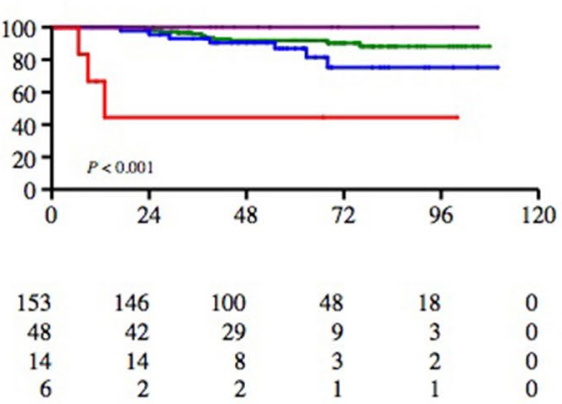

$\mathbf{f}$

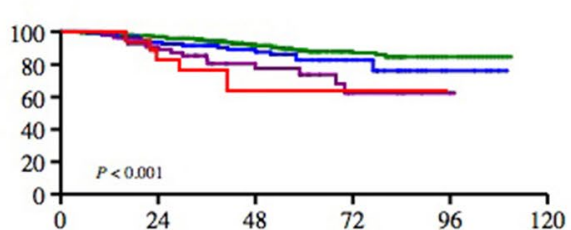

$\begin{array}{rrrrrr}460 & 432 & 224 & 107 & 24 & 0 \\ 114 & 98 & 62 & 32 & 5 & 0 \\ 56 & 50 & 28 & 9 & 2 & 0 \\ 18 & 14 & 5 & 4 & 0 & 0\end{array}$

h

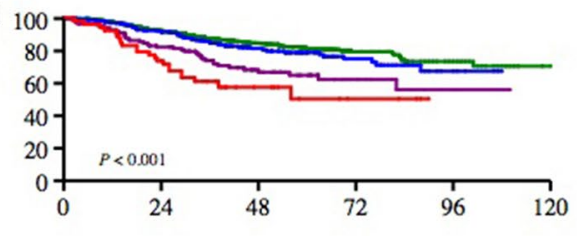

$\begin{array}{rrrrrr}877 & 772 & 398 & 149 & 42 & 1 \\ 221 & 192 & 101 & 47 & 9 & 0 \\ 126 & 100 & 47 & 15 & 4 & 0 \\ 55 & 39 & 11 & 4 & 0 & 0\end{array}$

Time after diagnosis (months)

Fig. 8 Kaplan-Meier survival estimates for NPC patients at different clinical stages according to two staging systems and stratified by subtypes according to the proposed classification. The OS differed significantly according to subtype of the proposed classification for patients at different clinical stages classified according to the 1992 China staging system $(P=0.031, \mathbf{a} ; P=0.002, \mathbf{c} ; P<0.001$, e and $\mathbf{g})$ and the 1997 AJCC staging system (all $P<0.001, \mathbf{d}, \mathbf{f}$, and $\mathbf{h}$ ), respectively. The log-rank test was used to calculate $P$ values 
Table 5 Clinical characteristics of 3893 patients with advanced NPC who were treated with different therapeutic modalities

\begin{tabular}{|c|c|c|c|}
\hline \multirow{2}{*}{$\begin{array}{l}\text { Characteristic } \\
\text { Total (cases) }\end{array}$} & \multirow{2}{*}{$\begin{array}{l}\text { RT alone } \\
1077\end{array}$} & \multirow{2}{*}{$\begin{array}{l}\mathrm{RCT} \\
2816\end{array}$} & \multirow[t]{2}{*}{$P$ value } \\
\hline & & & \\
\hline \multicolumn{3}{|l|}{ Age (years) } & $<0.001^{\dagger}$ \\
\hline Median (range) & $48(11-90)$ & $47(10-85)$ & \\
\hline \multicolumn{3}{|c|}{ Follow-up time (months) } & $<0.001^{\dagger}$ \\
\hline Median (range) & $60(2-120)$ & $52(2-120)$ & \\
\hline \multicolumn{3}{|l|}{ Sex [cases (\%)] } & $0.120^{*}$ \\
\hline Male & $785(72.9)$ & $2120(75.3)$ & \\
\hline Female & $292(27.1)$ & $696(24.7)$ & \\
\hline \multicolumn{3}{|c|}{ Clinical stage [cases (\%)] } & $<0.001^{*}$ \\
\hline III & $685(63.6)$ & $1144(40.6)$ & \\
\hline IV & $392(36.4)$ & $1672(59.4)$ & \\
\hline \multicolumn{3}{|c|}{ Proposed classification [cases (\%)] } & $<0.001^{*}$ \\
\hline EC & $622(57.8)$ & $1845(65.5)$ & \\
\hline MSEC & $228(21.2)$ & $531(18.9)$ & \\
\hline SC & $178(16.5)$ & $320(11.3)$ & \\
\hline SCC & $49(4.5)$ & $120(4.3)$ & \\
\hline \multicolumn{3}{|c|}{ WHO classification [cases (\%)] } & $<0.001^{*}$ \\
\hline NKUC & $889(82.5)$ & $2215(78.6)$ & \\
\hline NKDC & $160(14.9)$ & $560(20.0)$ & \\
\hline KSCC & $28(2.6)$ & $41(1.4)$ & \\
\hline \multicolumn{3}{|l|}{ OS rate (\%) } & $<0.001^{\S}$ \\
\hline 5-year (95\% Cl) & $64.8(61.7-67.6)$ & $75.6(73.8-77.3)$ & \\
\hline
\end{tabular}

$N P C$ nasopharyngeal carcinoma, $R T$ radiotherapy, $R C T$ radiochemotherapy, EC epithelial carcinoma, MSEC mixed sarcomatoid-epithelial carcinoma, SC sarcomatoid carcinoma, SCC squamous cell carcinoma, WHO World Health Organization, NKUC non-keratinizing undifferentiated carcinoma, NKDC non-keratinizing differentiated carcinoma, $K S C C$ keratinizing squamous cell carcinoma, OS overall survival, $\mathrm{Cl}$ confidence interval

* Chi square test

† Student's $t$ test

$\S$ Log-rank test

patients with the SC subtype (HR $=0.97,95 \% \mathrm{CI}=0.74-$ 1.28, $P=0.826$; Fig. 9c). However, this was also likely the case for those with the SCC subtype (HR $=0.63,95 \%$ $\mathrm{CI}=0.40-0.98, P=0.048$; Fig. $9 \mathrm{~d})$. A multivariate Cox analysis showed that after adjustment for age, sex, clinical stage, and the WHO classification, both therapeutic modality and the proposed classification were significant predictors of the survival of advanced NPC patients (Table 6).

Due to the unbalanced distribution of clinical stages III and IV between the RCT and RT alone groups (Table 5), we repeated this analysis after the included cases were restricted to either stage III or stage IV NPC. Consistent with the results for all advanced NPC patients, significant differences in the 5-year OS rates were observed between patients who were treated with RCT and RT alone within the subtypes of EC and MSEC after the cases were restricted to either stage III or stage IV cancers (data not shown).

\section{Discussion}

Prognostic evaluation is pivotal for making decisions concerning appropriate treatment delivery. In our present study, we developed an NPC histopathologic classification that can distinguish among the different subtypes with clinically and statistically significant differences in the 5-year OS rate, even after multivariate adjustment for or stratification by TNM stage. Compared with the training and retrospective validation cohorts, the estimated 5 -year OS rate was most likely higher in the prospective validation cohort due to the more widespread delivery of RCT to NPC patients seen between 2007 and 2011 at SYSUCC. An additional explanation for the higher 5-year OS rate in this cohort $(83.5 \%$ vs. $68.7 \%$ and $73.3 \%$ in the other two cohorts) is that it also had the shortest median follow-up time (41 vs. 68 and 68 months in the other cohorts), which was due partly to the more recent diagnosis of these patients.

Considerable controversy surrounds the WHO classification and its prognostic value [22]. The WHO KSCC subtype accounts for one-third to one-half of all NPC cases in western populations, and this subtype is associated with a worse prognosis compared with nonkeratinizing carcinoma [23, 24]. However, studies have consistently failed to show that the distinction between the WHO NKDC and NKUC subtypes has any clinical relevance [6-8]. These two subtypes comprise more than $95 \%$ of NPCs in endemic areas, including in our study population $[4,25]$.

RCT has consistently produced a survival benefit compared with RT alone, and 5-year OS rates of approximately $70 \%$ have been achieved by RCT in patients with stages III and IV NPC [12-15, 18, 26-30]. Lewis et al. [31] reported that $10.9 \%$ of patients received inadequate adjuvant therapy and $4.4 \%$ received inadequate radiotherapy based on the US National Comprehensive Cancer Network head-and-neck guidelines for recurrent or residual head-and-neck cancer. Exploratory analyses in our study indicated that compared with RT alone, RCT may improve outcomes in patients with advanced disease for the EC and MSEC subtypes, and possibly for the SCC subtype, but no evidence of an effect for the SC subtype was found. The worse prognosis of patients with the SC and SCC subtypes suggests that the current therapeutic methods are insufficient for these disease subtypes. Our results indicate that the proposed classification system may enable a more tailored approach for optimal clinical treatment decisions, especially for the SC and SCC subtypes, in which patients may need aggressive therapies such as high-dose irradiation, neoadjuvant and/or 


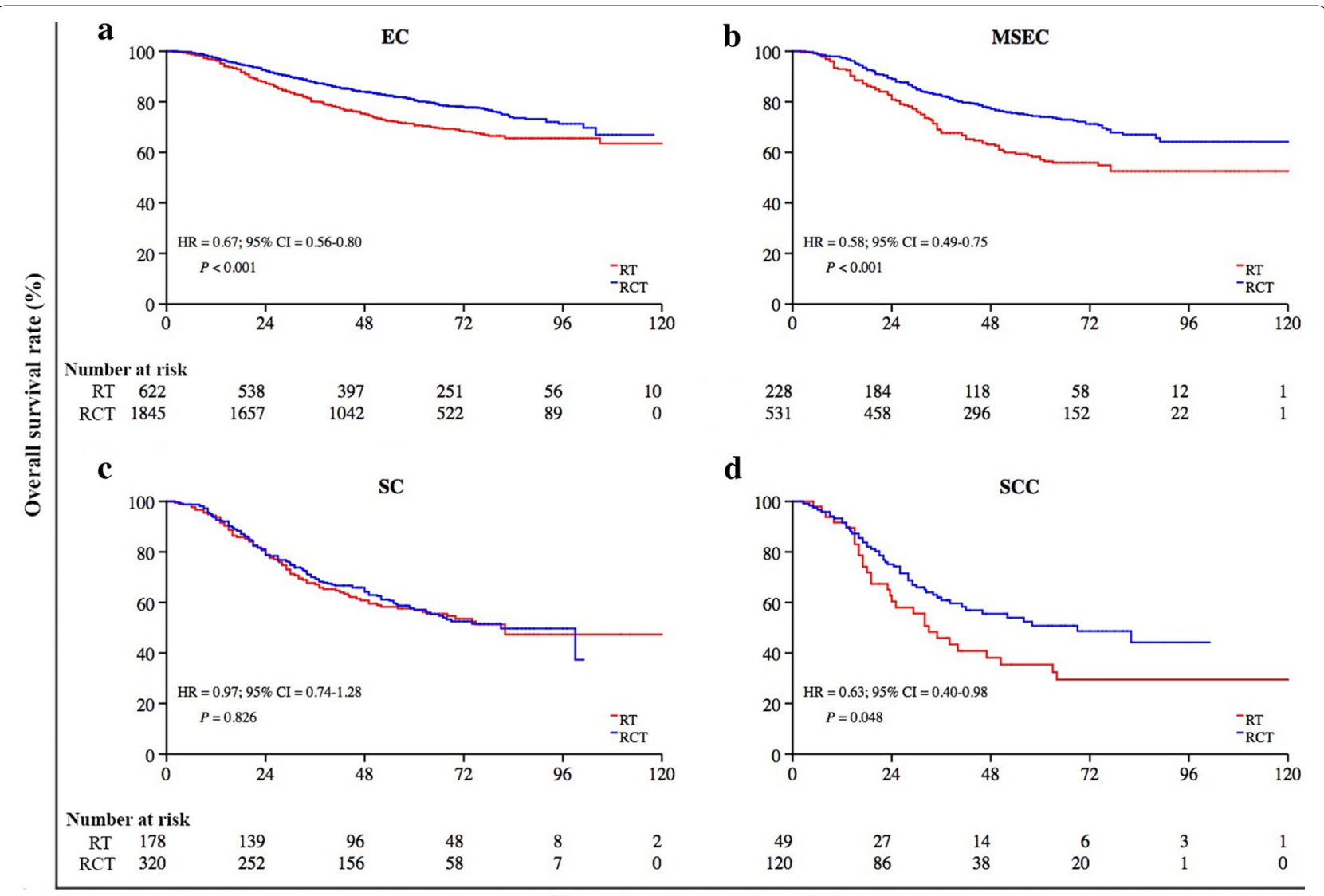

Time after diagnosis (months)

Fig. 9 Kaplan-Meier survival estimates for the 3893 advanced NPC patients with different proposed subtypes who underwent radiochemotherapy (RCT) or radiotherapy (RT) alone. RCT significantly improved survival compared to RT alone for patients with EC $(P<0.001$, a) and MSEC $(P<0.001$, b), but not for patients with SC $(P=0.826$, $\mathbf{c})$; this was also likely the case for those with SCC $(P=0.048$, d). The log-rank test was used to compute $P$ values. Hazard ratios (HRs) with 95\% confidence intervals (Cls) were computed for each type (RCT versus RT alone)

adjuvant chemotherapy, surgery, and molecularly targeted therapy to yield additional therapeutic gains. The efficacy of such therapies will require randomized clinical trials that stratify patients by histopathologic subtypes.

In the present study, the MRI and CT information of some patients are unavailable, particularly for the training cohort. The 1997 AJCC staging system is not applicable for these patients. Therefore, the 1992 China staging system was used. Our data clearly showed that different staging systems consistently predict the prognosis of NPC patients. Differences between these two staging systems mainly involve the classification of the borders of the tumor and lymph nodes in advanced disease [32]. Furthermore, Hong et al. [33] reported a high degree of similarity (72.1\%) between the 1992 China staging system and the 5th edition of the AJCC staging system for NPC; the latter was then developed into the 6th AJCC system with minimal modification. In another study that compared the 5, 6, and 7th editions of the AJCC staging system in a total of 985 NPC patients, a minimal magnitude of improvement in prognostication was found [34]. Therefore, the 1992 China and 1997 AJCC staging systems were both acceptable for the prediction of prognosis.

A limitation to consider is in terms of generalizability because all included patients were from NPC-endemic areas in East Asia. The replication of our results in nonAsian patients needs to be confirmed for the use in clinics worldwide. We had incomplete follow-up data for $24 \%$ of the cohort, which raises the possibility of selection bias; however, differential follow-up based on histopathologic subtype was unlikely. The distribution of clinical stages differed between the RCT and RT alone groups, in which the patients were not randomized. Therefore, the efficacy of therapeutic strategies in patients with different histopathologic subtypes should be explored in future randomized clinical trials with complete follow-up. We cannot exclude the possibility that shorter survival in some groups is due to comorbidity, performance status, or some other unmeasured prognostic factors, rather than histopathologic subtype. However, no prior studies 
Table 6 Cox proportional regression analysis of associations between clinical characteristics and OS in 3893 patients with advanced NPC

\begin{tabular}{|c|c|c|c|c|c|c|c|c|}
\hline \multirow[t]{2}{*}{ Characteristic } & \multicolumn{2}{|c|}{ OS rate (\%) } & \multirow{2}{*}{$\begin{array}{l}\text { Unadjusted } \\
\text { HR }\end{array}$} & \multirow[t]{2}{*}{$95 \% \mathrm{Cl}$} & \multirow[t]{2}{*}{$P$ value } & \multirow{2}{*}{$\begin{array}{l}\text { Adjusted } \\
\mathrm{HR}^{\mathrm{a}}\end{array}$} & \multirow[t]{2}{*}{$95 \% \mathrm{Cl}$} & \multirow[t]{2}{*}{$P$ value } \\
\hline & 5-year & $95 \% \mathrm{Cl}$ & & & & & & \\
\hline \multicolumn{9}{|c|}{ Therapeutic modality } \\
\hline RT & 64.8 & $61.7-67.6$ & 1.00 & Reference & & 1.00 & Reference & \\
\hline $\mathrm{RCT}$ & 75.6 & $73.8-77.3$ & 0.67 & $0.59-0.76$ & $<0.001$ & 0.64 & $0.56-0.72$ & $<0.001$ \\
\hline \multicolumn{9}{|c|}{ Proposed classification } \\
\hline EC & 78.3 & $76.5-80.0$ & 1.00 & Reference & & 1.00 & Reference & \\
\hline MSEC & 69.1 & $65.4-72.5$ & 1.48 & $1.27-1.72$ & $<0.001$ & 1.43 & $1.22-1.67$ & $<0.001$ \\
\hline SC & 57.6 & $52.8-62.1$ & 2.24 & $1.91-2.62$ & $<0.001$ & 2.13 & $1.81-2.51$ & $<0.001$ \\
\hline SCC & 46.4 & $37.8-54.5$ & 3.14 & 2.49-3.96 & $<0.001$ & 3.99 & $2.97-5.35$ & $<0.001$ \\
\hline \multicolumn{9}{|l|}{ Age } \\
\hline$\leq 47$ years & 77.7 & $75.7-79.6$ & 1.00 & Reference & & 1.00 & Reference & \\
\hline$>47$ years & 66.8 & $64.4-69.1$ & 1.58 & $1.39-1.78$ & $<0.001$ & 1.51 & $1.34-1.71$ & $<0.001$ \\
\hline \multicolumn{9}{|l|}{ Sex } \\
\hline Male & 71.5 & $69.7-73.3$ & 1.00 & Reference & & 1.00 & Reference & \\
\hline Female & 75.2 & $72.1-78.0$ & 0.81 & $0.69-0.93$ & 0.003 & 0.82 & $0.71-0.95$ & 0.008 \\
\hline \multicolumn{9}{|l|}{ Clinical stage } \\
\hline III & 76.8 & $74.7-78.8$ & 1.00 & Reference & & 1.00 & Reference & \\
\hline IV & 68.3 & $66.0-70.5$ & 1.38 & $1.22-1.56$ & $<0.001$ & 1.48 & $1.31-1.68$ & $<0.001$ \\
\hline \multicolumn{9}{|c|}{ WHO classification } \\
\hline NKUC & 72.6 & $70.8-74.2$ & 1.00 & Reference & & 1.00 & Reference & \\
\hline NKDC & 73.2 & $69.5-76.7$ & 0.98 & $0.83-1.15$ & 0.780 & 0.97 & $0.81-1.15$ & 0.690 \\
\hline KSCC & 60.9 & $47.7-71.9$ & 1.66 & $1.13-2.41$ & 0.009 & 0.47 & $0.29-0.76$ & 0.002 \\
\hline
\end{tabular}

$N P C$ nasopharyngeal carcinoma, OS overall survival, $C l$ confidence interval, $H R$ hazard ratio, $R T$ radiotherapy, $R C T$ radiochemotherapy, EC epithelial carcinoma, MSEC mixed sarcomatoid-epithelial carcinoma, SC sarcomatoid carcinoma, SCC squamous cell carcinoma, WHO World Health Organization, NKUC non-keratinizing undifferentiated carcinoma, NKDC non-keratinizing differentiated carcinoma, KSCC keratinizing squamous cell carcinoma

a All models were adjusted for the proposed classification, age, sex, therapeutic modality, clinical stage, and WHO classification

have demonstrated an association between histopathologic features and comorbidity or performance status, which indicates that they are unlikely to be strong confounders. Finally, complex gene networks may be the underlying mechanisms for the morphologic traits; thus, genomic analyses are warranted for further investigation and verification to elucidate the molecular basis for the proposed classification.

In conclusion, this multi-center study proposes an NPC histopathologic classification system that can significantly distinguish prognosis beyond clinical stage among non-squamous subtypes of NPC. The finding that RCT improves survival over RT alone in patients with advanced EC and MSEC suggests that more attention should be paid to the improvement of clinical outcomes for the SC and SCC subtypes, which are associated with a worse prognosis.

\section{Authors' contributions}

JYS was the principal investigator and participated in the research design, study management, review of the report, and final approval. YXZ and ATCC were involved in conception of the study, study design, data interpretation, and manuscript writing. HYW was involved in the data collection, analysis, data interpretation, and manuscript writing. CPW, MKMK, LG, CNQ, HJ, XDZ, LZ, CYC, TXL, SLC, HQM, GC, PYH, IE, HKN, and JTSW were involved in the followup data collection, data interpretation, and patient recruitment. JYS, JTL, KFT, YLC, ML, HZZ, JHH, PQM, AJH, HGL, CKS, JSGH, and YFF were involved in the pathologic slide review. QS, MYH, and SF were involved in provision of study materials and data collection. WY, ETC, and HOA were involved in data analysis and interpretation. All authors contributed to the drafting of the manuscript. All authors read and approved the final manuscript.

\section{Author details}

${ }^{1}$ State Key Laboratory of Oncology in South China; Collaborative Innovation Center for Cancer Medicine, Sun Yat-sen University Cancer Center, \#651 Dongfeng Road East, Guangzhou 510060, Guangdong, P. R. China. ${ }^{2}$ Department of Molecular Diagnostics, Sun Yat-sen University Cancer Center, Guangzhou 510060, Guangdong, P. R. China. ${ }^{3}$ Department of Pathology, National Taiwan University Hospital, National Taiwan University College of Medicine, Taibei 10002, Taiwan, P. R. China. ${ }^{4}$ Department of Anatomical and Cellular Pathology, Hong Kong Cancer Institute and Sir YK Pao Centre for Cancer, Faculty of Medicine, The Chinese University of Hong Kong, Hong Kong 10871, P. R. China. ${ }^{5}$ Department of Pathology, Singapore General Hospital, Singapore 169608 , Singapore. ${ }^{6}$ Department of Nasopharyngeal Carcinoma, Sun Yat-sen University Cancer Center, Guangzhou 510060, Guangdong, P. R. China.

${ }^{7}$ Department of Pathology, Sun Yat-sen University Cancer Center, Guangzhou 510060, Guangdong, P. R. China. ${ }^{8}$ Division of Epidemiology, Department of Health Research and Policy, Stanford University School of Medicine, Stanford, CA 94305, USA. ${ }^{9}$ Health Sciences Practice, Exponent, Inc., Menlo Park, CA 94025, USA. ${ }^{10}$ Department of Otolaryngology, National Taiwan University Hospital, National Taiwan University College of Medicine, Taibei 10002, Taiwan, P. R. China. ${ }^{11}$ Department of Clinical Oncology, Hong Kong Cancer 
Institute and Sir YK Pao Centre for Cancer, Faculty of Medicine, The Chinese University of Hong Kong, Hong Kong 10871, P. R. China. ${ }^{12}$ Division of Radiation Oncology, National Cancer Center, Singapore 169610, Singapore. ${ }^{13}$ Department of Radiation Oncology, Cancer Institute and Hospital, Chinese Academy of Medical Sciences, Beijing 100730, P. R. China. ${ }^{14}$ Department of Radiation Oncology, The Affiliated Hospital of Bengbu Medical College, Bengbu 233030, Anhui, P. R. China. ${ }^{15}$ Department of Pathology, Cancer Institute and Hospital, Chinese Academy of Medical Sciences, Beijing 100730, P. R. China. ${ }^{16}$ Department of Radiation Oncology, Guangxi Medical University, Nanning 530021, Guangxi, P. R. China. ${ }^{17}$ Department of Pathology, Hunan Provincial Cancer Hospital, Changsha 410013, Hunan, P. R. China. ${ }^{18}$ Department of Radiation Oncology, Sun Yat-sen University Cancer Center, Guangzhou 510060, Guangdong, P. R. China. ${ }^{19}$ Department of Pathology, Fujian Provincial Cancer Hospital, Fuzhou 350014, Fujian, P. R. China. ${ }^{20}$ Department of Pathology, The First Affiliated Hospital, Sun Yat-sen University, Guangzhou 510080, Guangdong, P. R. China. ${ }^{21}$ Department of Pathology, Sun Yat-sen Memorial Hospital, Sun Yat-sen University, Guangzhou 510120, Guangdong, P. R. China. ${ }^{22}$ Department of Pathology, The Third Affiliated Hospital, Sun Yat-sen University, Guangzhou 510630, Guangdong, P. R. China. ${ }^{23}$ Department of Experiment Research, Sun Yat-sen University Cancer Center, Guangzhou 510060, Guangdong, P. R. China. ${ }^{24}$ Department of Medical Epidemiology and Biostatistics, Karolinska Institutet, Stockholm 17177 , Sweden. ${ }^{25}$ Departments of Microbiology and Tumor Biology Center, Karolinska Institutet, Stockholm 171 77, Sweden. ${ }^{26}$ Department of Epidemiology, Harvard School of Public Health, Boston, MA 02115, USA.

\section{Acknowledgements}

This study was supported by grants from the National High Technology Research and Development Program of China (863 Program) (No. 2012AA02A501), the Chinese State Key Basic Research Project (No. 2011CB504805), and the National Natural Science Foundation of China (No. 81272952 and No. 81472522).

The authors thank all pathologists and technicians for their help in retrieving H\&E slides for reclassification of nasopharyngeal carcinoma. These include personnel from the Department of Pathology, Guangdong General Hospital, Guangzhou, Guangdong, P. R. China (Yan-Hui Liu); the Department of Pathology, Guangzhou First Municipal People's Hospital, Guangzhou, Guangdong, P. R. China (Hong Du); the Department of Pathology, the Second Affiliated Hospital of Guangzhou Medical College, Guangzhou, Guangdong, P. R. China (Zhuo-Fang Hao); the Department of Pathology, Shenzhen People's Hospital, Shenzhen, Guangdong, P. R. China (Min Zuo and Xiao-Mei Wang.); the Department of Pathology, Dongguan People's Hospital, Dongguan, Guangdong, P. R. China (Yi-Sheng Lu); and all other local hospitals in Guangdong Province, P. R. China.

\section{Competing interests}

The authors declare that they have no competing interests.

Received: 18 December 2015 Accepted: 6 April 2016

Published online: 05 May 2016

\section{References}

1. Cao SM, Simons MJ, Qian CN. The prevalence and prevention of nasopharyngeal carcinoma in China. Chin J Cancer. 2011;30(2):114-9.

2. Jia WH, Huang QH, Liao J, Ye W, Shugart YY, Liu Q, et al. Trends in incidence and mortality of nasopharyngeal carcinoma over a 20-25 year period (1978/1983-2002) in Sihui and Cangwu counties in southern China. BMC Cancer. 2006;6:178.

3. Zhang LF, Li YH, Xie SH, Ling W, Chen SH, Liu Q, et al. Incidence trend of nasopharyngeal carcinoma from 1987 to 2011 in Sihui County, Guangdong Province, South China: an age-period-cohort analysis. Chin J Cancer. 2015;34(1):15.

4. Chang ET, Adami HO. The enigmatic epidemiology of nasopharyngeal carcinoma. Cancer Epidemiol Biomarkers Prev. 2006;15(10):1765-77.

5. Vokes EE, Liebowitz DN, Weichselbaum RR. Nasopharyngeal carcinoma. Lancet. 1997;350(9084):1087-91.
6. Farias TP, Dias FL, Lima RA, Kligerman J, de Sa GM, Barbosa MM, et al. Prognostic factors and outcome for nasopharyngeal carcinoma. Arch Otolaryngol Head Neck Surg. 2003;129(7):794-9.

7. Heng DM, Wee J, Fong KW, Lian LG, Sethi VK, Chua ET, et al. Prognostic factors in 677 patients in Singapore with non disseminated nasopharyngeal carcinoma. Cancer. 1999;86(10):1912-20.

8. Shanmugaratnam K. Histological typing of nasopharyngeal carcinoma. IARC Sci Publ. 1978;20:3-12.

9. Chan AT, Teo ML, Lee WY, Kwan WH, Choi PH, Johnson PJ. The significance of keratinizing squamous cell histology in Chinese patients with nasopharyngeal carcinoma. Clin Oncol (R Coll Radiol). 1998;10(3):161-4.

10. Krueger GR, Kottaridis SD, Wolf H, Ablashi DV, Sesterhenn K, Bertram G. Histological types of nasopharyngeal carcinoma as compared to EBV serology. Anticancer Res. 1981;1(4):187-94.

11. Hsu HC, Chen CL, Hsu MM, Lynn TC, Tu SM, Huang SC. Pathology of nasopharyngeal carcinoma. Proposal of a new histologic classification correlated with prognosis. Cancer. 1987;59(5):945-51.

12. Wee J, Tan EH, Tai BC, Wong HB, Leong SS, Tan T, et al. Randomized trial of radiotherapy versus concurrent chemoradiotherapy followed by adjuvant chemotherapy in patients with American Joint Committee on Cancer/International Union against cancer stage III and IV nasopharyngeal cancer of the endemic variety. J Clin Oncol. 2005;23(27):6730-8.

13. Lee AW, Lau WH, Tung SY, Chua DT, Chappell R, Xu L, et al. Preliminary results of a randomized study on therapeutic gain by concurrent chemotherapy for regionally-advanced nasopharyngeal carcinoma: NPC-9901 Trial by the Hong Kong Nasopharyngeal Cancer Study Group. J Clin Oncol. 2005;23(28):6966-75.

14. Hui EP, Ma BB, Leung SF, King AD, Mo F, Kam MK, et al. Randomized phase II trial of concurrent cisplatin-radiotherapy with or without neo adjuvant docetaxel and cisplatin in advanced nasopharyngeal carcinoma. J Clin Oncol. 2009;27(2):242-9.

15. Chan AT, Leung SF, Ngan RK, Teo PM, Lau WH, Kwan WH, et al. Overall survival after concurrent cisplatin-radiotherapy compared with radiotherapy alone in locoregionally advanced nasopharyngeal carcinoma. J Natl Cancer Inst. 2005;97(7):536-9.

16. Huang PY, Cao KJ, Guo X, Mo HY, Guo L, Xiang YQ, et al. A randomized trial of induction chemotherapy plus concurrent chemoradiotherapy versus induction chemotherapy plus radiotherapy for locoregionally advanced nasopharyngeal carcinoma. Oral Oncol. 2012;48(10):1038-44.

17. Lee AW, Tung SY, Chua DT, Ngan RK, Chappell R, Tung R, et al. Randomized trial of radiotherapy plus concurrent-adjuvant chemotherapy vs radiotherapy alone for regionally advanced nasopharyngeal carcinoma. J Natl Cancer Inst. 2010;102(15):1188-98.

18. Chen L, Hu CS, Chen XZ, Hu GQ, Cheng ZB, Sun Y, et al. Concurrent chemoradiotherapy plus adjuvant chemotherapy versus concurrent chemoradiotherapy alone in patients with locoregionally advanced nasopharyngeal carcinoma: a phase 3 multicentre randomised controlled trial. Lancet Oncol. 2012;13(2):163-71.

19. Min H, Hong M, Ma J, Zhang E, Zheng Q, Zhang J, et al. A new staging system for nasopharyngeal carcinoma in China. Int J Radiat Oncol Biol Phys. 1994;30(5):1037-42.

20. Chua DT, Sham JS, Wei WI, Ho WK, Au GK. The predictive value of the 1997 American joint committee on cancer stage classification in determining failure patterns in nasopharyngeal carcinoma. Cancer. 2001;92(11):2845-55.

21. Ma J, Liu L, Tang L, Zong J, Lin A, Lu T, et al. Retropharyngeal lymph node metastasis in nasopharyngeal carcinoma: prognostic value and staging categories. Clin Cancer Res. 2007;13(5):1445-52.

22. Hua YJ, Chen MY, Qian CN, Hong MH, Zhao C, Guo L, et al. Postradiation nasopharyngeal necrosis in the patients with nasopharyngeal carcinoma. Head Neck. 2009;31(6):807-12.

23. Fu KK. Prognostic factors of carcinoma of the nasopharynx. Int J Radiat Oncol Biol Phys. 1980;6(4):523-6.

24. Mesic JB, Fletcher GH, Goepfert H. Megavoltage irradiation of epithelial tumors of the nasopharynx. Int J Radiat Oncol Biol Phys. 1981;7(4):447-53.

25. Wang HY, Sun BY, Zhu ZH, Chang ET, To KF, Hwang JS, et al. Eight-signature classifier for prediction of nasopharyngeal [corrected] carcinoma survival. J Clin Oncol. 2011;29(34):4516-25. 
26. Baujat B, Audry H, Bourhis J, Chan AT, Onat H, Chua DT, et al. Chemotherapy in locally advanced nasopharyngeal carcinoma: an individual patient data meta-analysis of eight randomized trials and 1753 patients. Int J Radiat Oncol Biol Phys. 2006;64(1):47-56.

27. Huang PY, Cao KJ, Guo X, Mo HY, Guo L, Xiang YQ et al. A randomized trial of induction chemotherapy plus concurrent chemoradiotherapy versus induction chemotherapy plus radiotherapy for locoregionally advanced nasopharyngeal carcinoma. Oral Oncol. 2012;48 (in press).

28. Chen YP, Wang ZX, Chen L, Liu X, Tang LL, Mao YP, et al. A Bayesian network meta-analysis comparing concurrent chemoradiotherapy followed by adjuvant chemotherapy, concurrent chemoradiotherapy alone and radiotherapy alone in patients with locoregionally advanced nasopharyngeal carcinoma. Ann Oncol. 2015;26(1):205-11.

29. Kong L, Zhang YW, Hu CS, Guo Y. Neoadjuvant chemotherapy followed by concurrent chemoradiation for locally advanced nasopharyngeal carcinoma. Chin J Cancer. 2010;29(5):551-5.

30. Blanchard P, Lee A, Marguet S, Leclercq J, Ng WT, Ma J, et al. Chemotherapy and radiotherapy in nasopharyngeal carcinoma: an update of the MAC-NPC meta-analysis. Lancet Oncol. 2015;16(6):645-55.
31. Lewis $C M$, Hessel AC, Roberts $D B$, Guo YZ, Holsinger FC, Ginsberg LE, et al. Prereferral head and neck cancer treatment: compliance with national comprehensive cancer network treatment guidelines. Arch Otolaryngol Head Neck Surg. 2010;136(12):1205-11.

32. Lin ZX, Yang ZN, Zhan YZ, Xie WJ, Li GW, Feng HT. Application study of the 2008 staging system of nasopharyngeal carcinoma. Ai Zheng. 2009;28(10):1029-32 (in Chinese).

33. Hong MH, Mai HQ, Min HQ, Ma J, Zhang EP, Cui NJ. A comparison of the Chinese 1992 and fifth-edition international union against cancer staging systems for staging nasopharyngeal carcinoma. Cancer. 2000;89(2):242-7.

34. Lee AW, Ng WT, Chan LK, Chan OS, Hung WM, Chan CC, et al. The strength/weakness of the AJCC/UICC staging system (7th edition) for nasopharyngeal cancer and suggestions for future improvement. Oral Oncol. 2012;48(10):1007-13. 